\title{
THE ENVIRONMENTAL EDUCATION DIMENSIONS FOR SUSTAINABLE DEVELOPMENT
}

\author{
Martian Iovan, Ph.D. \\ „Vasile Goldis” Western University of Arad \\ E-mail: miovan@uvvg.ro
}

\begin{abstract}
Based both on a historical approach regarding the evolution of the environmental education between 1960 and present days, and on empirical research as well, the author proves that the efficiency of the environmental education could be much higher if included within the broader sphere of moral and civic education and if it is driven by a more extensive ideal sprung from the fundamental human right to a clean and well preserved environment, by the contemporary moral and civil values. The author pleads and motivates for an increased capitalization of the humanities and social sciences, of art, of environmental ethics and aesthetics in shaping "the ecological personality" of the tomorrow people. When shaping these personality traits through environmental education activities, one must emphasize the importance of practice and applied actions aimed to protect the environment, and in general, the practice of civic-moral education methods.
\end{abstract}

Keywords: environmental education; sustainable development; environmental issues; moral values.

\section{Introduction}

The increasing interest of the educators, the researchers in Education Sciences, the decision-makers in the public policies for the protection of the environment, the managers concerned with environmental conservation and protection, is closely related to human health and welfare, both locally / national and on a global scale as well. All over the world, more and more people do realize the destructive effects of the ecological crisis that endangers the health, the quality of the human life, the biodiversity conservation, the historical evolution of human civilization and this awareness has led to strengthening the beliefs of the educators, the specialists in environmental issues and the decision-makers of educational policies regarding the environment, meaning it is imperative to focus our attention and efforts on optimizing the curriculum, from the national curriculum to any school unit at all educational levels and forms and particularly, to increase the formal and nonformal environmental efficiency / effectiveness. On the other hand, the increased advertising in the public sphere of the third generation of fundamental human rights - i.e. the human right to a clean and well preserved environment - enhanced the public claims for the international, national and local authorities, responsible in solving the environmental problems.

Due to these conditions, the formal and informal environmental education has become the subject of multidisciplinary research which, since 1960, led to 
curriculum reform, teaching innovations, creating and promoting educational activities designed to generate superior performance in the work practice of the environmental education. The environmental education has gradually evolved from a monodisciplinary to an interdisciplinary, systemically approached and value oriented education. The frequent curricular upgrades included and valued the scientific information about man, society, nature, the environment in general, and their interconnections viewed in their continuous historical development, purposes for the environmental education and ways of achieving it as well, encompassing all levels of learners with a special emphasis on exercises and practical activities organized in the classroom, in school and out of school (UNESCO-UNEP, 1985). In the contemporary international context, the environmental education is getting closer and closer to the concept of education for the sustainable development of the planet, for the green economy and society.

This study intends to prove that the outcomes of the environmental education could be much higher due to a wider capitalization of the humanities and social sciences, of art, of the fiction literature, aesthetics, ethics, of moral and civic education methods and procedures - actions generally managed by a philosophy of ecological values, respectively an eco-philosophy. It is acknowledged that the man is the author of pollution-generating actions, of the environmental degradation in different forms, of the extinction of different species of animals and plants, of the degradation of beautiful landscapes in the abiotic environment, of the imbalance in the functioning of the ecosystems, the irrational depletion of natural resources etc. Therefore, it is the man who should be reshaped through the environmental education according to an assumed educational ideal. The concise result of the environmental education is the shaping of the ecological personality on the individual level. This is directed by the moral, civic, aesthetic and ecological values, having a strong intrinsic motivation and volition, affection and respect attitudes for the natural, social, cultural and spiritual environment, so that this kind of personality can freely decide about solving the environmental issues through specific actions and personal involvement. Those having this kind of personality shall not confine within a theoretical and reflexive horizon, but they will be capable of action, creativity and innovation in solving the environmental problems; the ecological personality represents a character with firm attitudes towards the environment, who easily shifts from intentions to actions and who achieves its environmental awareness by triggering personal activities meant to protect and preserve the environment.

The theoretical-demonstration approach in the present study is led by the philosophy of nature and the history of society, by the human relations within society, and with the biotic and abiotic environment, in a continuous historical dynamic; the method is confirmed by the results of an empirical research using the 
Iovan, M. (2015)

The environmental education dimensions for sustainable development

questionnaire method, the focus group, the Delphi method, the case analysis, the conversation - especially among young students and MA students, age 18-20 years.

\section{The Ethical and Civic Coordinates of the Environmental Education for a Sustainable Development}

In a period of only half a century, the environmental education, being closely related to the environmental public policy, has experienced a more rapid, coherent and effective development following the warnings initiated by universities, specialized research institutes, media, and governmental organizations. Post World War II and the 50s, the destructive effects concerning the quality and health of people's lives and the future of mankind caught the public attention by the continuous developing of the ecological imbalances, the continental water pollution of seas and oceans, the air and soil pollution, the pollution in agriculture, the food pollution (by chemical processing), the transport and storage of radioactive materials etc.

One of the mankind's first strong warning regarding the need for government intervention to preserve and protect the biosphere, the abiotic nature, was launched by the International Union for the Conservation of Nature and Natural Resources, which was founded in Switzerland in 1948, with offices in Morges and Gland. The same year, in a Paris conference, the first use of the term "environmental education" was used at an international level and strong arguments were brought to its usefulness for the national education systems and even for all people. Subsequently, different scientific analyses and debates were held in numerous universities, various conferences were organized concerning the conflict between the civilization and the environment due to the reckless human interventions.

Based on extensive investigations and thorough analysis developed during 1968 1972, a team of researchers from Boston University (USA), led by the Meadows professors, published "The Limits to Growth" - the first Report of the Club of Rome, promoting a new philosophy and explaining that the environment is a dynamic open system facing finite and limited resources - some even nonrenewable - and the human tendency to exploit them with an alarming increase for indefinite time. Such warnings stirred concern feelings for the fate of humanity. All over the world, specialists, journalists and professors discussed and analyzed such issues that provoked heartfelt emotions and true worries: What will the world do after depletion of non-renewable resources? What actions should the authorities take regarding the demographic growth, the land degradation and desertification or about pollution? How the harmful effects of pollution on human health will be stopped? How mankind should effectively intervene so that the biodiversity and the abiotic nature are preserved? In other terms, what must be done to alleviate and overcome the ecological crisis? 
Iovan, M. (2015)

The environmental education dimensions for sustainable development

Facing such difficult issues, different international organizations (such as UN, UNESCO, OAA, etc.), governments, NGOs, public authorities, etc. responded by developing public policies in their area of expertise, in order to solve and especially, to prevent the environmental issue. On these circumstances, the environmental education policies (or the environmental education) were developed and mostly fell under the responsibility of relevant ministries and of education institution of all kinds.

However, during recent decades, such tasks have been also assumed by media, NGOs, churches, environmental organizations, voluntary associations in the area of environmental education. The demand for an environmental education in school at all ages and forming a pro-environment public opinion was sustained at the UN Conference in June 1972, in Stockholm, accepted and endorsed by the international community. Since 1975, UNESCO has activated the International Program on Environmental Education, and on its basis, the Tbilisi Conference was held in October 1977. The documents of the Conference consisted of defining the goal, objectives and guiding principles of environmental education, recommendations for the world's states to implement its content in the formal and non-formal educational structure. As from the Tbilisi Conference, the environmental education is defined as: The permanent process of forming a generation who is aware of the local and global environment, who is concerned about the environment and the ecological issues. It is essential that the individuals of the new generation acquire knowledge, skills, attitudes, motivations and commitments which will enable them - individually and collectively - to solve present and future environmental problems. (UNESCO, 1987:6).

The Tbilisi Conference agreed that the environmental education it is not just a newly-developed distinct educational discipline, but a complex field of education meant to be integrated into various related disciplines and curricular experiences. The ideas and recommendations of the Conference have established an open path for environmental sciences specialists, educators, psychologists, sociology of education researchers, ethicists, philosophers, etc. in relation to the eco-education. The progress of the environmental education continued in theory and in practice with strong connections to the environmental policies initiated by various governments and public authorities, and to the development of ecology, natural sciences, social and human sciences, philosophy of life and values, and not least, the eco-ethics.

During the last three decades, the environmental educational policies and the effective process of environmental education at all educational levels, in any teaching structure - schools, universities, human communities - and for different age periods, focused first on the consciousness, information and training, awareness, ecological and related different sciences learning. In this respect, a 
Iovan, M. (2015)

The environmental education dimensions for sustainable development

renowned author stated: "the environmental education is based on awareness with the purpose of protecting the natural world ... awareness of all people and the effective ecological training of managers. We emphasize the absolute need for a civic awareness." (Parvu, C., 1999: 563).

Such situations arise several questions as: Can the environmental education be resumed to training - be it as comprehensive, aimed to lead to the acquisition of ecological knowledge and to environmental awareness, to training skills and intellectual abilities in people able to solve the environmental issues arising amid the ecological crisis? If prevalent within a society, is it enough to know this part of reality so the public policies of the environmental education, in micro and macro levels, are effective and efficient? Do the intellectual and technical capabilities of the trained individuals suffice in order to achieve the ultimate goal of the environmental education? Technocratic experts and educators, sociologists, philosophers and politicians sought the answers to such questions. Obviously, the technocratic solutions, namely those which consider science and specialized knowledge development, the progress of technology and management as the main way for solving the environmental issues, have not fully satisfied the philosophers, eco-ethicists, sociologists and educators. In their research and organizing public debates, researchers began to focus the eco-education on individuals, on their moral, psychological, personal, attitudinal personality from a broader perspective of mankind's history.

The results were presented in a high-level summit of prime-ministers, Rio de Janeiro, 1992, UNCED. The 1992 Rio Summit represents a historic moment for the development of the environmental education viewed from the objective perspective of environmental globalization, of the contemporary value - centered philosophy, of the fundamental human rights and, above all, the human right to healthy and balanced environment. The conference enacted a statement of principles and a long-time action plan for sustainable development, expended during the $21^{\text {st }}$ century (Agenda 21). The national or international environmental education of all types, shapes, and levels, was integrated into the sustainable development process. The course of sustainable development was planned in order to restore, maintain and consolidate a long-term rational balance of the economic growth and the natural environment integrity for the benefit of future generations (SNDDR, 2008) - as the first and most important responsibility of states, international organizations, NGOs, people, communities, businesses, in order to develop an ecologically viable society (Lavieille, J. - M., 2010).

From the theoretical perspective of the globalization of society and of the new philosophy of sustainable development of the planet in this century - unanimously accepted by governments around the world - it was expected that the environment education turn towards sustainable development, to develop people's 
environmental awareness and culture through the practical implementation of Agenda 21 in all educational structures as lifelong education, included in the world-wide sustainable development education for every state and nation. This concept represents the foundation of the guiding principles concerning the environmental education activities, thus the development and implementation of the environmental education policies in most countries. These principles are (Toth, M., 2002: 20-21):

- the concept of environment is broadly approached, including, besides the biosphere, the abiotic environment and society with all its components: economics, infrastructure, political system, culture, spiritual life, customs, traditions, collective mind, the legal system, namely the man-made environment through all the social activities;

- it is a continuous process developed throughout the human life, from kindergarten to old age, in different forms and ways, in and outside the educational system;

- it is a multi and interdisciplinary education, guided by an overall conception of the world and life that integrates specific knowledge not only of the various natural sciences, but also of social and human sciences, art, literature, ethics, aesthetics, environmental law, philosophy and human experience;

- it focuses on current and future issues of the environment, addressed in terms of local, regional, national and international, with the teamwork of the trained, sharing experience in the field of environmental protection, with critical approaches;

- the training and development of the moral and civic responsibility for the environmental education students and their ability to identify answers for the ecological issues, to make specific decisions, to be actively involved in the environmental activities locally or professionally;

- the environmental education aims to promote sensitivity to the environment, training abilities, habits and skills to protect the environment, shaping positive attitudes towards the environment and adhesion to the contemporary ecological values at any age;

- training the moral and civic attitudes, the critical and innovation thinking for the environmental education;

- the environmental education principles are compatible with the emergence of very different situations such as: training, learning, assessment, cooperation, building skills and eco-attitudes. For that purpose, in any educational structure, the practical activities have a prevalent role, being initiated and organized for specific habitats with ecological issues.

The last two decades research in science education, humanities and social science, educational philosophy and environmental ethics have led to rethinking the concept of environmental education due to the influences of the World Summit on 
Iovan, M. (2015)

The environmental education dimensions for sustainable development

Sustainable Development in Johannesburg (Rio + 10), August 26 to September 4, 2002, and the United Nations Conference on Sustainable Development - 2012 (Rio +20 ). Analyzing in the context of globalization the environmental education's evolution since 1970 until the emergence of sustainable development education, and, then, in the latest period, being centered on the development of the "green economy" (as "green economy" is the descendant of the "sustainable development" concept), anyone can realize that the initial stage focused on knowledge capitalization of biology, geography, chemistry, physics in order to raise awareness to the ecological issues and sensitize the trained. Subsequently, the environmental education has expanded the scope in an inter - and transdisciplinary perspective, becoming more consistent and being guided by a comprehensive eco- philosophy and a moral-civic values system. Cognitive objectives have been associated with psychomotor, behavioral and attitudinal objectives. As for the national education systems, the environmental education has evolved to priorities its objectives, placing first and foremost the training of environmental skills, feelings and motivation - guided by the moral values. An environmental ethic was promoted connecting the active citizenship. This development required the exploitation of new sciences and disciplines in order to fulfill more efficiently the environmental education objectives and to build "the green economy". Therefore, the formative role of humanities and social sciences, economics, law, literature, arts, civic culture gradually amplified.

As a result of the broadly approach of the environmental concept - including, besides the biosphere, the abiotic environment, the space, and the socio-sphere with all its artificial components, the civilization, the economy, the culture, the spiritual life, the institutional infrastructures and superstructures, the legal and moral rules and regulations - the environmental education activities have become more complex. Taking initiatives and decisions in this area, organizing the activities, evaluating the results required higher skills in environmental protection, as well as a long-term responsibility and vision, oriented by the sustainable development values, humanity and environmental ethics. Nowadays, the environmental education has become a complex system of moral, civic and aesthetic valuesoriented activities and an education that promotes human rights and values, centered on man and the benefit of mankind. All environmental education efforts aim directly to protect and preserve the habitats, to maintain the ecological balance and circuit, and indirectly, to ensure the quality of human life, the society health and sustainability, guaranteeing the fundamental human right to a clean and wellpreserved environment for today's and future generations. In this context, the environmental education could be redefined as: "being oriented towards preserving the biosphere, and within the biosphere protecting and maintaining human life, while the goal represents the emotional, rational, aesthetic and moral foundation of 
the human habits system showing respect for nature, the man-built environment, the social background and for people, by imposing awareness towards the environment and a lifestyle characterized by environmental responsibility " (Toth, M., 2002:26-27).

The environmental education, as it should be designed and accomplished today, includes all environmental education practices that form the ecological personality profile, with positive attitudes towards environmental issues, will and character traits, a moral-civic valued orientation and specific skills on which the individual can engage in the community activities to solve environmental issues, regulated by an intrinsic motivation and an ethical duty or responsibility. Meanwhile, the environmental education harmonizes legal and ethical standards and also the development of citizenship. World-wide, the democratic states' citizens possess and claim their environmental rights and obligations a fortiori as they have a more emancipated civic and environmental consciousness. The present stage of mankind shaped the human right to a clean, healthy and balanced environment - planned as a fundamental human right. The society's sustainable development and the achievement of the green economy include the general recognition of human rights, and in particular, the right to the environment, which fundamentally guarantees the human first right - the right to life. Therefore, the environmental education will not achieve its aim without the understanding of national and international environmental law. The individuals' environmental behavior, initiatives, decisions and environmental policies are regulated by the environmental law and by specific legal rules (Rajsp, Martina \& Fosnaric, Samo, 2014). Reflected in the environmental protection and the preservation, the active civic consciousness and people's attitudes represent the corollary of the environmental education. Or, this outcome involves following the environment legal regulations, the civic and ethical values - resulting in an individual and collective responsibility applying not only to worldwide states, but also to each and every human being of the planet (Dutu, M., 2012: 48). Thus the involuntarily destructive force exerted by the human species on the environment, in its entirety or on its component entities, turns back on the man himself and endangers his life in danger, threatening the very existence and survival of mankind. People can cause harm to each other when acting reckless on the natural environment, the biotic and abiotic, and on the social environment, on the products of human civilization. Therefore, the environmental behavior of people, of social groups and human communities can be appreciated in ethical terms, from the moral values point of view. The ecological morality emerged on this background; it contains the people's values, principles, rules and guidelines in interaction with nature, with different entities of the environment, which are meant to be defended and protected for the benefit of people and happiness of mankind. Eco-ethics - an applied branch of general ethics deals with exploring and studying 
Iovan, M. (2015)

The environmental education dimensions for sustainable development

this reality (Elliot, R., 2006). The ecological ethics - perceived as a knowledge branch: "deals with the moral principles and rules that should govern the human relations with their environment and, especially, with the vast and complex process of biodiversity" (Puia et al., 2001).

Thus, questions such as: What good or bad people can do regarding nature? Are people obliged to transmit to the future generations the natural environment preserved as received from ancestors? Are people allowed to exterminate certain species of animals or plants, thereby disturbing several circuits and ecological balances? How free are people in the nature? Is nature our friend, partner or foe? It is moral to store radioactive waste near some conurbations? Do massive deforestation matter knowing that this phenomenon could lead to floods / landslides? Is it good to diminish the world's biodiversity because of people? The preservation of the biosphere could be more important than thousands of people who starve to death? Such questions may find answers from an ecological perspective founded on the ethical paradigm (Singer, P., 2006).

Concluding, we can state that the environmental education should be centered on man, on the formation of intrinsic motivation, on favorable attitudes towards the environment, on will and character, on the ecological personality profile - guided by the ethical duty and responsibility for the environment. Any grown-up perceived as a result of the environmental education, will behave in an environmentally ethical manner in its relations with the others when he/she will put above all the triumph of good for his peers and the community in spite of some momentary satisfactions, or when taking genuine ecological decisions, even these are against to his/hers interests or desires, when he/she integrates and harmonizes the environmental behavior within the complex process of building a "sustainable economy", a "green society". The prototype of such a personality, formed by the process of eco-education, can be identified today in an early stage, embodying the members of environmental groups who volunteer to solve the environmental problems.

\section{Instead of Conclusions}

- Following the evolution of the environmental education since 1970 and to date, we identified a qualitative enhancement and development by implementing interdisciplinarity in new and various educational practices at all ages, in formal and non-formal education, in national and international activities, gradually increasing the formative role of the humanities, arts, ethics, aesthetics, social and legal sciences. If at the initial stages, the environmental education focused on the transmission of natural sciences knowledge, in the recent decades, it has broadened the general objectives focusing on developing the environmentally friendly 
personality. The environmental education at all ages and fulfilling its ideal are guided by moral and civic values

- If in the 1970s, the environmental education objectives were focused on the nature's scientific knowledge and on training the ecological consciousness resulting from the acquisition of environmental scientific information, then - after the International Conference in Tbilisi - 1977, and especially after the Rio de Janeiro Conference - 1992, the goals of environmental education have been redefined beginning with the reassessment of the environment concept. In addition to the biosphere and the abiotic environment, man-made environment, material civilization, social and economic life, legal and moral system, culture, collective mind, aesthetics of biotic and abiotic environment have been introduced in the environment concept. The national education systems' curricula and institutions were reformed on this basis, with an increasingly contribution of social sciences and humanities, the arts, ethics, legal rules to protect the environment, or environmental aesthetics.

- From one decade to another, there has been a gradual process of democratization of the environmental education through the exponential growth of all ages and socio-professional categories beneficiaries due to its introduction in all levels of education - from pre-school to university and post-graduate, due to broadening and intensifying communication in the mass - media, especially radio, television and the Internet and also due to the increasing number of environmental organizations. Currently, the world population is mainly aware of the importance of environmental education for building a green society.

- The ideals of environmental education - as a reference guide for shaping the environmental policies, the improvement of the environmental education activities and the national curriculum or the choice of appropriate methods, procedures and techniques for training and modeling the ecological personality - must expand by focusing on the personality of the educated. The essential for shaping and defining the environmental education goals is not so much an environmental awareness training, but the development of the axiological dimensions of personality, the internalization of moral and civic values, feelings and beliefs connecting to the environment and the rejection of any individual or group behavior that can harm the environment, during the formation and strengthening of attitudes, will and character traits - the central point of the ecological personality. From this point of view, we agree with the reassessment and the development of pedagogy of Pestalozzi, Durckheim or J. Dewey - denoting an integrated approach of the environmental issues, teaching through information, feelings and beliefs, strengthening intrinsic motivation and the need to solve them - all implemented in practical activities in order to solve the environmental issues (Michel Kalff, 1977). Enhancing ecological knowledge does not guarantee efficiency for the 
Iovan, M. (2015)

The environmental education dimensions for sustainable development

environmental education but, mostly, training human will and the ability to act will do. A UNESCO - 1985 study shows that students from several developed European countries have highly superior environmental attitudes but the desire to act and to solve the environmental issues, or to be active in any environmental organizations is very low. The rift between a well-developed ecological consciousness of many citizens and the lack of involvement in environmental practice and protection can be overcome by switching the ratio between the knowledge and the practice of environmental activities, imposing the last and the priority use of specific methods of moral-civic education (the method of personal example, eco-ethic discussion, case analysis, moral conversation, exercise, teams cooperation, positive or negative moral sanction etc.).

- Nowadays environmental education must be designed and developed as human rights education, in particular the right to a clean, undegraded and preserved environment, to health, life and peace, as education for sustainable development and shaping the green society. In this context, the environmental education could become much more effective as it will connect with the broad scope of moral, civic and aesthetic education - without losing its identity, without failing to promote the generally accepted human values, i.e. Good, Beautiful, Just, Legal in human relations, between them and their environment.

\section{References}

1. Albulescu, Ion. (2008). Morala si educatie. Cluj - Napoca: EICON.

2. Bontas, Ioan. (2008). Tratat de pedagogie, VI-a edition, Bucuresti: Editura ALL.

3. Dietz,T., Kalof, L., Stern, P.C.(2002a). Gender, values, and environmentalism. Social Science Quarterly, 83: 353 - 372.

4. Dunlop,R.E. \& Jones, R.E. (2002). Environmental concern: Conceptual and measurement issues. In R.E. Dunlap, W. Michelson (eds.) Handbook of Environmental Sociology. Westport Green wood Press, pp. 482 - 524.

5. Dutu, Mircea. (2012). Politici publice de mediu, Bucuresti: Univers Juridic.

6. Elliot, Robert. (2006). Etica ecologica, in Tratat de etica, Peter Singer (Ed.). Iasi: Polirom, pp. $313-322$.

7. Elliot.R. \& Arran,G. (Coord). (1983). Environmental Philosophy: A Collection of Readings. Santa Lucia: University of Queensland Press.

8. Etzioni, A. (1988). The Moral Dimension: Toward a New Economic. New York: The Free Press.

9. Englerom, D. \& Yockers, D. (1994). A Guide to curriculum planning environmental education. 
Iovan, M. (2015)

The environmental education dimensions for sustainable development

10. European Comission. (2008). Attitudes of European citizens towards the environment. Special Eurobarometer.68.2, http://ec.europa.eu/public opinion/archives/ebs 295 en.pdf.

11. Guvernul Romaniei. (2008). Strategia Nationala pentru Dezvoltarea Durabila a Romaniei.

12. Hoggan, J. (2009). Climate cover-up. Vancouver/Toronto/Berkeley: D./ M. Publisher. Inc.

13. Iovan, Martian. (2014). Eco-Education: A Required Element of Public Policies for Sustainable Social and Economic Development, in Academicus International Scientific Journal. IX. pp. 14-29.

14. Lavieille, Jean - Marie. (2010). Droit international de l'environnement, $3^{\mathrm{e}}$ edition, Paris: Editions Ellipses.

15. Legros, Bernard \& Delplanche, J.-N. (2009). L'enseignement face a l'urgence ecologique. Bruxelles: Ed. Aden.

16. Mac, Ioan. (2003). Stiinta mediului. Cluj- Napoca: Editura Europontic.

17. Maxim, Aurel. (2008). Ecologie generala si aplicata, Cluj - Napoca: Editura Risoprint.

18. May, Theodore, S. (2000). Elements of Success in Environmental Education Through Practitioner Eyes. The Journal of EE, vol.31, Nr. 3.

19. Milton, K. (1996). Environmental and Cultural Theory: Exploring the Role of Antropology in Environmental Discourse, London: Routledge.

20. Mircescu, E. (2003). Educatie ecologica si voluntariatul in protectia mediului, Fundatia pentru Cultura si Educatie Ecologica ECOTOP \& Centrul National de Voluntariat PRO VOBIS, in http://www.repf.ro/uploaded/files/ file_a9f19a36a6.pdf, pp. 55- 103.

21. Monnier, Claire. (2012). Crise ecologique et education. Vers une nouvelle position ethique dans le lien entre l'homme et la nature, in Revue d'ethique et de theologie morale, 3 (no. 270), pp. 97 - 112.

22. Nistor, Laura. (2009). Sociologia mediului inconjurator. Aplicatii privind atitudini si comportamente in Romania. Cluj - Napoca: Presa Universitara Clujeana.

23. Orr,D.W. (1992). Ecological Literacy: Education and the transition to a postmodern world. SUNY Press.

24. Pana, C. (2000). Salvati Planeta Pamant. Bucuresti: Fundatia Terra Mileniul III.

25. Parvu, Constantin. (1999). Ecologie generala. Bucuresti: Editura Tehnica.

26. Puia,I., Soran,V., Ardelean, A., Maior, C., Puia, C.I. (1999). Elemente de ecologie umana. Arad: Vasile Goldis University Press. 
Iovan, M. (2015)

The environmental education dimensions for sustainable development

27. Rajsp,Martina, \& Fosnaric, Samo. (2014). Environmental Education and Its Impact on Children. Croatian Journal of Education. Vol. 16, No. 1, pages: 119148.

28. Stern, P.C., Dietz, T., Abel, T., Guagnano,G.A., Kalof, L. (1999). A value belief - norm theory of support social movements: the case of environmentalism. Human Ecology Review, 6: 81-97.

29. Sylvan,R. (1985). A Critique of Deep Ecology. Cambera: Research School of Social Sciences. Australian National University.

30. Schultz, P.W., Shriver,C., Tabanico,J.J., Khazian,A.M. (2004). Implicit connections with nature.Journal of Environmental Psychology, 24: 31-42.

31. Toth, Maria. (2002). Mediul inconjurator in educatie: educatia ecologica, educatia pentru mediu sau educatia privind mediul ? Cluj - Napoca: Editura Studium.

32. UNESCO. (1978). Intergovernmental Conference on Environmental Education. Final Raport. UNESCO - UNEP, Tbilisi, 14 - 24 october 1977, Paris: UNESCO.

33. UNESCO - UNEP. (1985). International Environmental Education Programme, Series 17. A Comparative Survey of the Incorporation of EE into School Curricula, ed. UNESCO.

34. UNESCO. (1987). International Strategy for Action in the field of Environmental Education and Training for the 1990 s. 1987: Nairobi/Paris, UNESCO.

35. UNESCO. (1986). L'education relative a l'environnement: Principes D`eisegnement et D`apprentissage: Programme international d education relative a l'environnement. UNESCO - PNUE,No. 20.

36. Vaideanu, G. (1988). Educatia la frontiera dintre milenii. Bucuresti: Editura Politica. 